\title{
Designing Autonomous Communities in Suburbs of Japan
}

\author{
Ikuyo Kikusawa $^{1} \&$ Kayoko Kondo $^{2}$
}

\begin{abstract}
:
In Japan, the suburbs face issues of depopulation, loss of culture, identical and interchangeable scenery due to the prevalence of chain stores and weak relationships between members of the community, contrast to the heavy concentration of populations in major cities. In tackling these issues, the conventional approach of community revitalisation leans heavily on economic, technological and administrative measures. This study proposes a new paradigm to address community autonomy of suburbs in order to accommodate contemporary values and lifestyles.

The proposed paradigm is based on the concept of the apron diagram developed by Arne Naess in deep ecology, one of the theories of environmental ethics. The diagram induces a paradigm shift in the way of thinking where individuals with different fundamental philosophies can share the principle and take diverse action for community autonomy. Also, the concept of Self-realisation proposed in deep ecology is applied to the premise of community governance. Self-realisation is the extension of the individual self to the larger Self and encompasses the essence of community autonomy.

This theoretical approach is supported by an interview survey conducted by the authors in Itoshima City, Fukuoka. The survey observed Self-realisation in the voluntary actions of community members.
\end{abstract}

Keywords: community autonomy, deep ecology, apron diagram, Self-realisation, suburb

\section{Introduction}

Heavy concentrations of population and industry in major cities have increased and even stabilised in Japan in contrast to the trends and efforts in other developed countries where a more balanced population distribution has been achieved (Yagi, 2015)(Motani, 2007). Population outflow to cities has caused depopulation in suburbs, which in part has triggered multiple issues such as a decline in the local economy, loss of culture, identical and interchangeable scenery due to prevalence of chain stores and weak relationships between community members, among other issues. In tackling these issues, the mainstream approach of community revitalisation focuses mostly on what to and how to accomplish this, with a bias towards economic, technological and administrative measures. This is echoed in the concepts of deep ecology that challenge the "short-term, shallow approach (that) stops before the ultimate level of fundamental change, often promoting technological fixes" (Drengson, 2012). Without a bold move to step out of this type of situation, a future community of suburbs ${ }^{1}$ may resemble a homogeneous and uniform community that merely maintains its functions.

1 Suburbs are located within the limits of the metropolitan district, but outside the city centre (Duncan \& Reiss, 1956) 
In response to the above issues, this study proposes a new paradigm drawing an ideological change for community autonomy to accommodate contemporary values and lifestyle. A family lifestyle including working styles and household makeup (single-parent family, lone elderly resident, etc.) has become diverse, and responding to various public needs is highly challenging. A new paradigm is based on the concept of a shared principle or vision, rather than fixing a set list of customary practices, in order to foster community autonomy achieving detailed mutual assistance and restoring local dynamism and community appeal. The concept is articulately elucidated using the apron diagram developed in deep ecology, a theory of environmental ethics.

\section{Conceptual Framework}

\subsection{Scope and Definition}

A community is considered to be a social unit in which people live in the same geographical location, share common perspectives, or jointly conduct activities. The level of community in this study is even smaller than the elementary boundary, a neighbourhood association called juchikai or chonaikai. The characteristics of a neighbourhood association in Japan are defined as 1) a household unit system, 2) geographical occupancy system, 3) participatory system that includes all households, 4) system inclusive of functions and 5) a terminal agency for public administration (Ito, 2007)(Kurasawa \& Akimoto, 1994). Neighbourhood associations as jichikaii or chonaikai did not exist in Western countries in the 1920s. ${ }^{2}$ The Western nations at the time tended to avoid the transfer of public roles to private entities. A Japanese-type neighbourhood association was viewed as obsolete and even appraised as a remnant of feudalism. Though obligatory participation, one of the four characteristics explained above, has been loosened in recent years, its coverage as a voluntary association is not comparable to any other entity around the world (Kurasawa \& Akimoto, 1994). Its role includes a diverse range of public services including community clean-up, collection of recyclables, sharing of local information, organisation of local festivals, distribution of administrative information from governments, disaster prevention action, and others (Cabinet Office, 2004a). The role of the municipal government, which is responsible for promoting the welfare of citizens, has also increased in the areas of medical care, nursing care, education, transport and disaster response, and anticipates an intensification of administrative cost per capita (Ministry of Internal Affairs and Communications, 2013). Despite the loss of population along with a shrinking number of children, the number of settlements remains unchanged, so that residents are scattered over a large area, with an increasing rate of one-person household (Ministry of Internal Affairs and Communications, 2013). Such situations make the provision of quality public services difficult for a local government. Thus, the expectations for communities like neighbourhood associations have risen to provide some public services in place of local municipalities. The basic position of the neighbourhood association is to enhance a selfhelp and mutual assistance mechanism within a community. This direction, where a local

2 According to a response to an inquiry to the Tokyo Institute for Municipal Research for the Bureau of Municipal Research in New York in 1925 
community acquires the potential for self-help, has become increasingly important in Japan. By expanding the array of services a community can mutually provide, the capacity of self-dependence expands. Autonomy at the neighbourhood association level is a key to tackling multiple issues for suburban communities. However, in modern society, participation in the community activities is not philanthropic; rather, it is considered to be an obligation that impose a burden on the individual for the following reasons: the number of double income families who have limited time to work in the community are on the rise especially in an urban community; and in a rural community where the rate of aging is high, the roles of community rest on a few relatively young households as elderly members become exempt from community duties.

What kind of communities are considered to be autonomous? Compared to less autonomous communities, autonomous communities are likely to (1) provide diverse services including a mix of industries, (2) demonstrate stronger civic leadership aside from local community government, (3) have a stronger sense of community cohesiveness and place attachment to their community, and (4) rate their community higher on measures of quality of life and sense of community (Keith C. Russell, 2001). The concept of apron diagram gives implications to develop the above features.

\subsection{Apron Diagram}

To apply the premises given by the above ethics to community autonomy, a pyramid diagram called an 'apron diagram' depicted in deep ecology is used. The apron diagram was developed to illustrate the characteristics and structure of the deep ecology movement (井上 2016), but it also helps to illustrate how a diverse range of people may act based on their own motives for community autonomy. The structure of an apron diagram comprises four levels: the ultimate premises, such as philosophy and religion on level 1; an underwriting platform on level 2; general normative consequences on level 3; and particular rules or decisions on level 4 (Figure 1). Many ultimate philosophies and diverse practices in the diagram are in close contact with one another through logical and genetic relations (Naess, 1995). Only the underwriting platform on the second level is common, while on the other three levels, fundamental philosophies (level 1), policy (level 2) and actions (level 3) taken by individuals are diverse. This encourages diversity on three levels. Instead of bundling people by actions, policies or goals, it is significant in that it allows them to think what would be the best contribution to the elements of the platform (level 2) and what approach works for individual persons. Inoue (2009) explains this concept as 'citizenhood' in which each person acknowledges social responsibility and makes his/her own decision (Inour, 2009). 


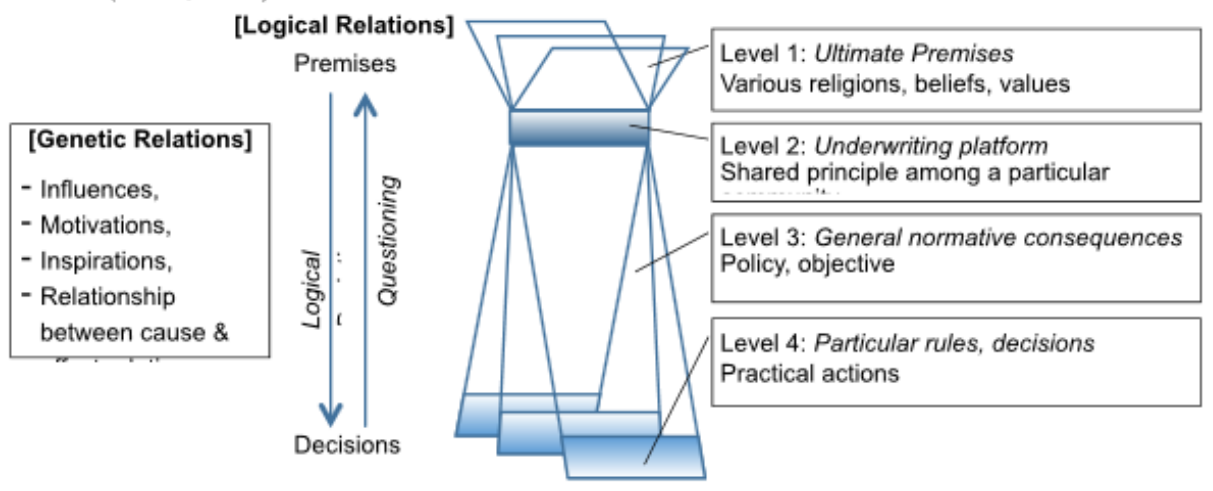

Figure 1 Apron Diagram

Under conventional approaches, people share activities and goals in order to tackle a particular issue. However, this has the potential to lose sight of original objectives as a result of repetitive actions that become customary procedures or in the process of the mere replication of action. This approach also influences the passive behaviour of people who tend to be reactive to the normative actions of community leaders or others'. Actions that do not reflect an individual's interest in fundamental problems never go beyond, nor reach a collective outcome.

\section{Discussion}

This section examines how community governance can be directed in an autonomous manner using the apron diagram. Two areas with rural and urban characteristics in the city of Itoshima are comparatively discussed.

\subsection{Characteristics of Case Communities}

Itoshima City in Fukuoka Prefecture is nestled between the sea and mountains, and is blessed with an abundance of fresh food. Located in the Fukuoka Metropolitan Area, it is home to a little less than 100,000 people and can be accessed within one hour from the city centre of Fukuoka City, the capital of Fukuoka Prefecture (Figure 2). Fukuoka City is Japan's fifth largest city and shows the largest rate of growth in the number of business establishments and population influx in the country (Fukuoka Asian Urban Research Center, 2016). The city is divided into 163 administrative divisions under 15 elementary school boundaries. The unit of a community discussed here is the administrative division called chonaikai or jichikai. The size of administrative divisions in Itoshima varies from over 2,000 to below 100 with an average population of about 600 people in each division. 


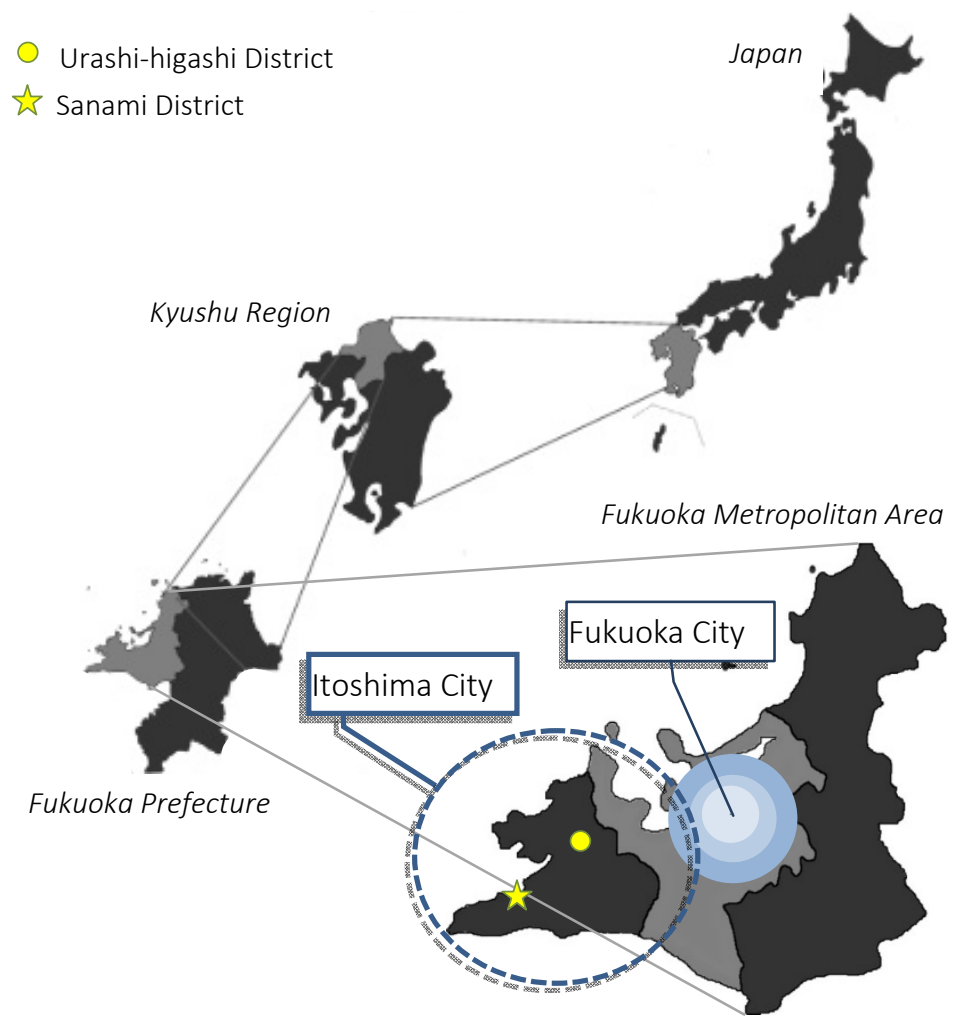

Figure 2 Location of Itoshima City in the Fukuoka Metropolitan Area ${ }^{3}$

A district called Sanami composed of 255 persons in 85 households is located in the far western area of Itoshima. The district, which has a $100 \%$ coverage rate for a neighbourhood association, is the location of an entire river basin of about $5 \mathrm{~km}$ from the source to the mouth of the river within its territorial boundary. The landscape of Sanami is shaped by the rural environment, and the area had long been rich in the cultivation of citrus fruits and tea bushes as well as livestock ranching. However, rapid economic growth had swept inefficient industries away, and people started commuting to the city centre (Yoshimaru, 2016). Today, despite the area's abundant rice paddies and orchards, there are no full-time farmers in the current generation. Like other typical suburbs, the area has faced the issue of depopulation with a relatively high aging rate of $32.7 \% .{ }^{4}$ An urgent issue is how existing rice paddies and fields, currently maintained by retired and semi-retired generations, will be taken care of in the future.

The second community, Urashi-higashi, is located in the city centre and is closer to Fukuoka City (Figure 2). The community has a population of 1,893 in 730 households, of which 610 households are members of the neighbourhood association (84\% participation rate). ${ }^{5}$ The area is characterised as a centre of urban facilities such as

\footnotetext{
${ }^{3}$ Figure adapted by author from Fukuoka Growth 2013-2014

${ }^{4}$ Rate of the population age 65 years or over

5 As of 2015
} 
commercial properties, recreation centres, offices, schools and clinics. The population of Urashi-higashi has steadily increased, and the aging rate is one of the lowest in the city at $17.0 \%$.

Approaches to community governance largely depend on the characteristics of the community. Although located in the same city, these two districts differ in the demography and mobility of the population, surrounding environments and historical backgrounds. The next section elaborates on how these districts with different local settings can achieve community autonomy using an apron diagram.

\subsection{Application of the Apron Diagram}

As described, the apron diagram is a useful theory and tool to expand the potential of diverse, voluntary and self-directive actions based on particular principles shared among a certain community. In the case of community governance, even if community members have a different philosophy or occupational background (level 1) it is possible to reach a shared principle (level 2). General normative consequences and policies (level 3) can be set by individual members depending on their interest and concerns such as environmental protection, welfare, and passing down cultural traditions, among others. Finally, members take part in community activities in line with the policies and goals they have set, for example, as a volunteer to assist in the collection of recycling waste, watching over children on their way to and from school, or leading practices of traditional dances for summer festivals (level 4).

When discussing what to include in 'principle' on level 2, a universal or common perspective must be achieved to a certain degree, although the principle may not necessarily be fixed or common to any community in any time over history. In the case of deep ecology, its eight principles - inherent value of human and nonhuman life, diversity of life forms, satisfaction of vital needs, decrease of human population, limited human interference, policy change, quality of life, and obligation of action - are positioned on the shared platform (Naess, 1973). Also, Inoue (2016) included his notions of 'environmental sustainability, social equity and ontological richness' on level 2 of the diagram in relation to the issue of environmental education. Both principles are fairly universal and reasonable if they are applied to community autonomy (with the exception of the 'decrease of human population' in deep ecology in the case of Japanese suburbs). Yet, 'Self-realisation', represented as one of the core philosophies of deep ecology, is more appropriate and insightful when considering the idea of community autonomy. One must be aware that Naess clearly differentiates the concept of 'self' of the narrow ego in the common usage from 'Self' (with a capital 'S') that "involves 'me' defined by the boundary of my skin, or 'mine' defined by the relations between me and others, and a larger set of beings and influences that might be called a total field of interaction" (Golley, 1987). This mindset provides significant practical meaning to modern society (Inoue, 1999). There should be some sort of area, place, landscape, things and persons that are considered to be one's 'Self. Rather than separating 'self' and 'others' (area, place, etc.) and connecting the two, the extension of 'Self' to 'others' is the starting point of community autonomy. This 'Self-realisation' can apply to both rural and urban communities, but its implications and perceptions may differ. For example, people in the rural community have a high regard for local natural settings, such as rivers and rice 
terraces. On the other hand, a boy that appeared in "Environmental Ethics in Urban Cities" by Yoshinaga (Yoshinaga, 2014) regarded a petrol station where he hung around in childhood as a place that offered him a place to relax because he feels comforted by the smell of exhaust fumes and gasoline. This indicates that people can extend their sense of self to something beyond the boundary of their skin, regardless of the characteristics of the community and individual interests. Both people would feel lost if part of their Self is hurt. This is the fundamental notion of community autonomy. An appropriate scale of community governance is determined by the scope where people are self-motivated to take action, not by a feeling of obligation.

\subsubsection{Rural Community}

For a rural community like Sanami with a history dating back over centuries, mutual assistance is an implicit principle. The people from the 85 households all know each other, and have a good recognition of current issues and the future outlook of the community. The committee members of the community have a strong sense of ownership and take a variety of voluntary actions to ensure the welfare of community members and passing down local cultural traditions. One community activity called a 'Salon' is a voluntary welfare group that aims to promote social engagement of the elderly. This Salon activity is promoted by the National Council of Social Welfare, and voluntary groups or local social welfare committees across the country set up gatherings in their local areas. In Sanami, the face-to-face nature of neighbourhood relationships is the reason behind the high level of participation. The organisers know where those people who should participate in the Salon live and the key persons who can drive and call on other elderly residents (Fujita, 2016). This face-to-face nature creates the sense of Self. It is considered that the Salon organisers deliver voluntary welfare services as a result of Self-realisation. This is an example where Self-realisation as the shared principle has brought about voluntary and autonomous actions that match the needs of the community.

\subsubsection{Urban Community}

On the other hand, in the community of Urashi-higashi located in the heart of Itoshima, the number of incoming residents has increased, including young families. Although the younger generation come to live in this community permanently or at least for a long period of time to raise their children, it is not easy to encourage them to become involved in community activities. The district head has made efforts to increase the number of children's events to involve families with children and draw them to parties with food and drink (Matsuda, 2016). A change has been observed among the younger community members. Although senior members take responsible positions such as the district head, secretary-general and accountant in the community, the younger members, as the parents of children, are appointed to a committee of the children association, a division under the community administrative structure. Through community events, young participants voluntarily started offering to help clean up at parties (Matsuda, 2016). Fostering relationships among residents is the first step to understand 'others' - in this case, neighbours and the community itself, which becomes part of Self. 
However, Self-realisation in the urban society is more complicated. In the 1970s, municipal governments promoted individual functional associations based on elementary school units. The roles of community have been partly taken over by such functional associations and the meaning of community has become diluted (Tanaka, 2007). Seemingly, there are no adverse effects as long as public services are provided. However, once such an organisational structure is established, the relationship between residents and functional associations becomes that of consumers and service providers. The quality of community is then judged by its functionality. Under such a social system, it is difficult to nurture the ownership of community members, and by necessity, limits the chance of Self-realisation. Meanwhile, there is the prospect that the new wave of younger generations will develop a higher level of consciousness for social work (Kikusawa, Masuda, \& Kondo, 2016). If the consciousness turns towards community governance, an urban community including young families gains a stronger autonomous state. In the past, a limited time was claimed to be the major reason for not participating in community activities (Cabinet Office, 2004b), but a contemporary society has been receiving a new perspective on the working style of young people. According to Lynda Gratton, the generations under 30s have a long-term perspective on their career, foreseeing the late retirement due to low pensions and a higher possibility of being burdened with educational loan (Gratton, 2013). On the reverse side, this made possible for those young people to dedicate their time for activities other than their work including social contribution.

Finally, looking back on the conditions of autonomous communities discussed earlier, the application of the apron diagram provides the base for the provision and recipient of diverse services while retaining diversity in policies and actions. Cohesiveness can be secured along with the involvement of diverse community members, strong civic leadership and a sense of community. As long as this situation is maintained, community members will show pride in their community.

\section{Conclusion}

This paper looks at the validity of a form of development seen in suburban communities in Japan. It is imperative that community autonomy be improved to shift the current paradigm of community governance. As a consideration for this issue, discussions were applied to the theory of deep ecology, which provides a practical and insightful analytical framework in the form of an apron diagram. The diagram induces a paradigm shift in the way of thinking in which individuals with different fundamental philosophies share a principle towards diverse actions. This approach can be applied to the modern lifestyles, which shows diversity in working styles and household makeup. As the principle of community governance - that Self-realisation advocated in deep ecology leads the extension of 'self' to larger 'Self' - is an indication of the essence of autonomy itself. In the case of Itoshima, the scope of Self is larger in rural suburbs, while there are prospects in urban suburbs for younger generations with high social consciousness to participate in community governance under the structure of the apron diagram. Thus, by drawing attention to one ideological perspective on community autonomy, the implications for designing more autonomous communities can be elaborated. And yet, 
there is room to delve into the feasibility of this approach and the co-existence of new and old paradigms in community autonomy for practical application.

\section{References}

Cabinet Office. (2004a). A Variety of Neighbourhood Association Activities. Retrieved July 15, 2016, from http://www5.cao.go.jp/seikatsu/whitepaper/h16/01_zu/zu301080.html

Cabinet Office. (2004b). Reasons for Not Participating in Chonaikai Activities.

Drengson, A. (2012). Some Thought on the Deep Ecology Movement. Retrieved from http://www.deepecology.org/deepecology.htm

Duncan, O. D., \& Reiss, A. J. (1956). Social Characteristics of Urban and Rural Communities. New York: John Wiley \& Sons.

Fujita, M. (2016, June 28). Personal Interview by the author.

Golley, F. B. (1987). Deep Ecology from the Perspective of Ecological Science. Environmental Ethics, 9(1), 45-55.

Gratton, L. (2013). How Technology is Transforming Work. Video presentation.

Keith C. Russell, C. H. (2001). Dimensions of Community Autonomy in Timber Towns in the Inland Northwest. Society \& Natural Resources, 14(1), 21-38.

Matsuda, S. (2015, October 13). Personal interview by the author.

Ministry of Internal Affairs and Communications. (2013). Report on the Reform of Mega City System and the Provision of Administrative Services by Municipalities. Retrieved from http://www.soumu.go.jp/main_content/000403632.pdf

Naess, A. (1973). The shallow and the deep, long-range ecology movement. A summary. Inquiry, 16(1), 95100.

Naess, A. (1995). The Apron Diagram. In A. Drengson \& Y. Inoue (Eds.), The Deep Ecology Movement: An Introductory Anthology (p. 75).

Yoshimaru, H. (2016, February 4). Personal interview by the author.

Ito, S. (2007). Jichikai - Chonaikai to Jumin Jichi (Jichikai - Chonaikai and Community Governance). Ronso, (5), 85-116.

Inoue, Y. (1999). Holistic na Sekaikan to Minshuteki Shiminteki Kachi-Deep Ecology to Bioregionalism wo megutte (Holistic World View and Democratic, Citizenery Values - Around Deep Ecology and Bioregionalism). In. Kankyo no Yutakasa wo Motomete (Seeking the Richness of the Environment: Mission and Movement).

Inoue, Y. (2009). Arne Naess nitori Deep Ecology undo toha nanideattanoka - tokuni undo no shushi, oyobi eco fascism ni kakawaru giron wo meguttei (What deep ecology movement is all about to Arne Naess - with a focus on the main purport of the movement, and discussion of ecofascism). Knkyo Shiso Kyoiku Kenkyu, 3.

Inoue, Y. (2016). Chapter 2 "Kankyo kyoiku no platform" toiu idea (The idea of "platform of environmental education". In Imamura, M. (Ed.), Kankyo Kyoikugaku no Kiso Riron (Fundamental theories of environmental education) (pp. 17-33). Houritsu bunkasha.

Kikusawa, I., Masuda, Y., \& Kondo, K. (2016). Factors Shaping Community Participation in Itoshima City. Study Report of Architectural Institute of Japan. Kyushu Branch. 3, Planning, (55), 385-388. Retrieved from http://ci.nii.ac.jp/naid/110010026381/

Yoshinaga, A. (2014). Toshi no kankyo rinri: jizokusei, toshi ni okeru shizen, amenity (Environmental Ethics of Urban Cities: Sustainability, nature in urban cities and amenity). Keiso Shobo.

Fukuoka Asian Urban Research Center. (2016). Fukuoka Growth 2016.

Kurasawa, S., \& Akimoto, R. (1994). Chonaikai to chiiki shudan (Chonaikai and local groups). Minervashobo.

Motani, K. (2007). Tokyo ni izon shinai kokudo kouzou no arikatai (National land structure independent from Tokyo). Retrieved from http://www.mlit.go.jp/kokudokeikaku/iten/onlinelecture/lec113.html

Tanaka, I. (2007). NPO to jichikai tou chiengata dantai no kyoudou ni yoru chiiki community saikouchiku no shoyouken (Conditions for restructure of local community through joint actions by NPO and territorial community including jichikai . Community Policy, 5, 98-120. 
Yagi, H. (2015). "Toshinkaiki" jidai ni okeru daitoshi no jinkou idou (population mobility in mega cities in the era of "Return to city centre"). Studies in Urban Cultures, 17, 68-80 